\title{
A produção cultural de estudantes estagiários em artes visuais: um contexto criativo de formação.
}

Production cultural students trainees in visual arts: a training creative context.

Selma Machado Simãoi

Universidade Estadual Paulista "Júlio de Mesquita Filho"

\begin{abstract}
Resumo
Este artigo trata da experiência de estágio e da produção cultural realizada a partir dele desenvolvida por estudantes matriculados no curso de Licenciatura em Artes Visuais do Instituto de Artes da Unicamp. As vivências plurais emergentes do campo do estágio possibilitaram a realização de relatos escritos voltados a diversos percursos criativos, entre eles àqueles que se dirigem a âmbitos memoriais e formadores. Deslocamentos materializados em objetos sensíveis que ampliaram os pontos de vista e as perspectivas das escolhas e das formas de trabalhar os conteúdos nas atividades do estágio em campo. Com a interlocução de: ideias, vivências pedagógicas e produções culturais inseridas no universo epistemológico de saberes específicos foi possível conquistar ganhos sobre saberes práticos e teóricos pertinentes à disciplina. Assim, além de ressaltar a criação poética e a autoria a experiência evidenciou também a importância da pesquisa na atuação do estágio em artes.
\end{abstract}

Palavras chave Artes Visuais, Estágio, Docência.

\section{Abstract}

This article deals with the internship experience and cultural output from it developed by students enrolled in the Bachelor of Visual Arts Institute of Unicamp Arts. Emerging experiences plural stage field permitted to make written reports aimed at different creative paths, including those that address memorials and trainers areas. Displacements materialized in sensitive objects that expanded the views and perspectives of choices and ways of working the content on Stage activities in the field. With the interlocution: ideas, pedagogical experiences and inserted cultural productions in the epistemological universe of specific knowledge it was possible to achieve gains on practical knowledge and relevant theoretical discipline. Thus, in addition to emphasizing the poetic creation and authoring experience also highlighted the importance of research in stage performance in arts.

Keywords Visual Arts, Stage and Teaching.

Revista Digital do LAV - Santa Maria - vol. 10, n. 2, p. 140 - 161 - mai./ago. 2017 ISSN 1983 - 7348 http://dx.doi.org/10.5902/1983734827402 


\section{Introdução}

No segundo semestre de 2015 vivenciei uma experiência interessante de co-formação com os alunos do Curso de Licenciatura do Instituto de Artes da Universidade Estadual de Campinas na disciplina de Estágio Pedagógico II do Departamento de Artes Plásticas. Tendo sido convidada para ministrar palestras e atividades de supervisão para a turma de estágio em Artes Visuais, iniciamos a proposta de experienciar conjuntamente processos de descoberta e construção do conhecimento. Como assevera Paulo Freire: "...quem ensina aprende ao ensinar e quem aprende ensina ao aprender." (2002, p. 25). Apoiando-me nesse pensamento do autor, penso que como quem inicia o artista é a obra e quem inicia o pesquisador é a pesquisa, também quem inicia o professor é o aluno.

Ana Angélica Albano (2015, p. 14) chamou de curto-circuito perceptivo o fenômeno capaz de promover novas relações do artista com sua obra quando o mesmo estabelece contato com outros trabalhos, imagens, ou estímulos. De forma análoga, esse processo citado pela autora se desenvolvia em nossos encontros que tratavam de suas vivências como estagiários. Momentos nos quais os estudantes podiam comunicar suas impressões advindas no campo de estágio expressando-as através da forma oral, escrita ou por imagens criadas por eles. Assim, as experiências comunicadas no grupo, incitavam a curiosidade, inspiravam a produção em artes e a elaboração de práticas educacionais. Interesses capazes de produzir inovações, recriações e outros processos transformadores que culminavam em aprendizados diferenciados. Jácques Ranciére traduz essa ideia com o conceito de "partilha do sensível":

Denomino partilha do sensível o sistema de evidências sensíveis que revela, ao mesmo tempo, a existência de um comum e dos recortes que nele definem lugares e partes respectivas. Uma partilha do sensível fixa portanto, ao mesmo tempo, um comum partilhado e partes exclusivas (RANCIÉRE, 2004, p.12).

Uma dinâmica de relatos vindos dos fenômenos emergentes do campo de estágio movimentava nossos encontros. A cada depoimento apresentado, sucessivamente íamos configurando um cenário prático e teórico dos vários ambientes nos quais cada um desses estudantes realizavam seu estágios. Inúmeras informações iam sendo relatadas, como por exemplo, as diferentes formas que as instituições atendiam os estudantes para realizarem seus estágios. Nos encontros, alguns questionamentos destacavam-se entre os demais, tais como: O estágio de docência em arte, além de outras instâncias pode ser vivenciado como uma experiência sensível e criadora capaz de fomentar a produção a 
objetos poéticos? Dada à importância da mediação em artes que contempla diversas modalidades artísticas, como a arte contemporânea e a arte popular, seria possível facilitar a aproximação do público envolvido a essas manifestações? Quais seriam as principais informações teóricas e empíricas necessárias para fundamentar a prática de atividades dirigidas a essas finalidades específicas?

Todas essas inquietações foram discutidas e através dessas discussões os estudantes criaram propostas de práticas de ensino pensadas a partir de seus campos de estágios. Inspirados nessas vivências foram gerados uma série de trabalhos em desenho e pintura que seguiam a poética de cada um. Sabemos que as produções culturais dos diferentes grupos se apoiam na história cultural que os torna visíveis, assim como, os sujeitos autores dessas produções (CHARTIER, 1990, 2001; CERTEAU, 1996). As produções individuais dos estudantes materializaram objetos culturais singulares elaborados através de criações e re-criações originadas pelas reflexões e circunstâncias empíricas do estágio. Para contribuir com a formação do docente em artes Rita Irwin propõe uma inter-relação de três "formas de pensamento": a teoria, a prática e a poesis, pois segundo ela, essas "identidades" são "conectadas e integradas" (2009, p. 88-89). A autora elucida que elas correspondem ao ensino, à pesquisa e a criação em arte, Ou seja, consiste no trabalho do artista-pesquisador-professor (artist-researcher-teacher) baseado na proposta metodológica da $\mathrm{A} / \mathrm{r} /$ tografia. Rita Irwin afirma que a integração desta complexidade de categorias entrelaça conceitos, atividades e sentimentos e declara que: "... viver a vida de um artista que também é um pesquisador e professor é viver uma vida consciente, uma vida que permite abertura para a complexidade que nos rodeia", uma vida que nos possibilita uma escolha consciente de "perceber as coisas diferentemente" (Ibid, p. 96). A partir destas reflexões, inicio este texto descrevendo algumas experiências criativas, questionadoras e poéticas vivenciadas pelos estudantes de estágio ilustradas por seus relatos e pelas imagens de suas produções gráficas e pictóricas. Nos interstícios dessas apresentações, sigo tecendo reflexões teóricas sobre o ensino de artes, a formação docente e o estágio. Finalizo o texto com algumas reflexões sobre o estudo realizado. Assim sendo, este artigo se volta à educação das sensibilidades pautada na produção de sentidos advinda de objetos culturais singulares de autoria dos próprios estudantes estagiários em artes. 


\section{Os (entre)meios da experiência.}

Em busca de rememorar instâncias nas quais a arte tivesse participado da vida dos estudantes solicitei que respondessem a seguinte pergunta: Como a arte participou da minha infância? A ideia foi pautada na pretensão de desenvolver práticas significativas para o estágio, pois supondo que a partir de relatos de suas vidas pessoais relacionados à arte, os estudantes pudessem fazer conexões afetivas positivas de suas lembranças com as práticas que desenvolveriam no estágio.

Assim, memórias, episódios autobiográficos e imagens elaboraram autorretratos, sinceros e singulares. Esta aquarela de Elton Takumi Kawamorita (fig. 01) traz o encanto do imaginário infantil através da representação da brincadeira que cria e recria sonhos:

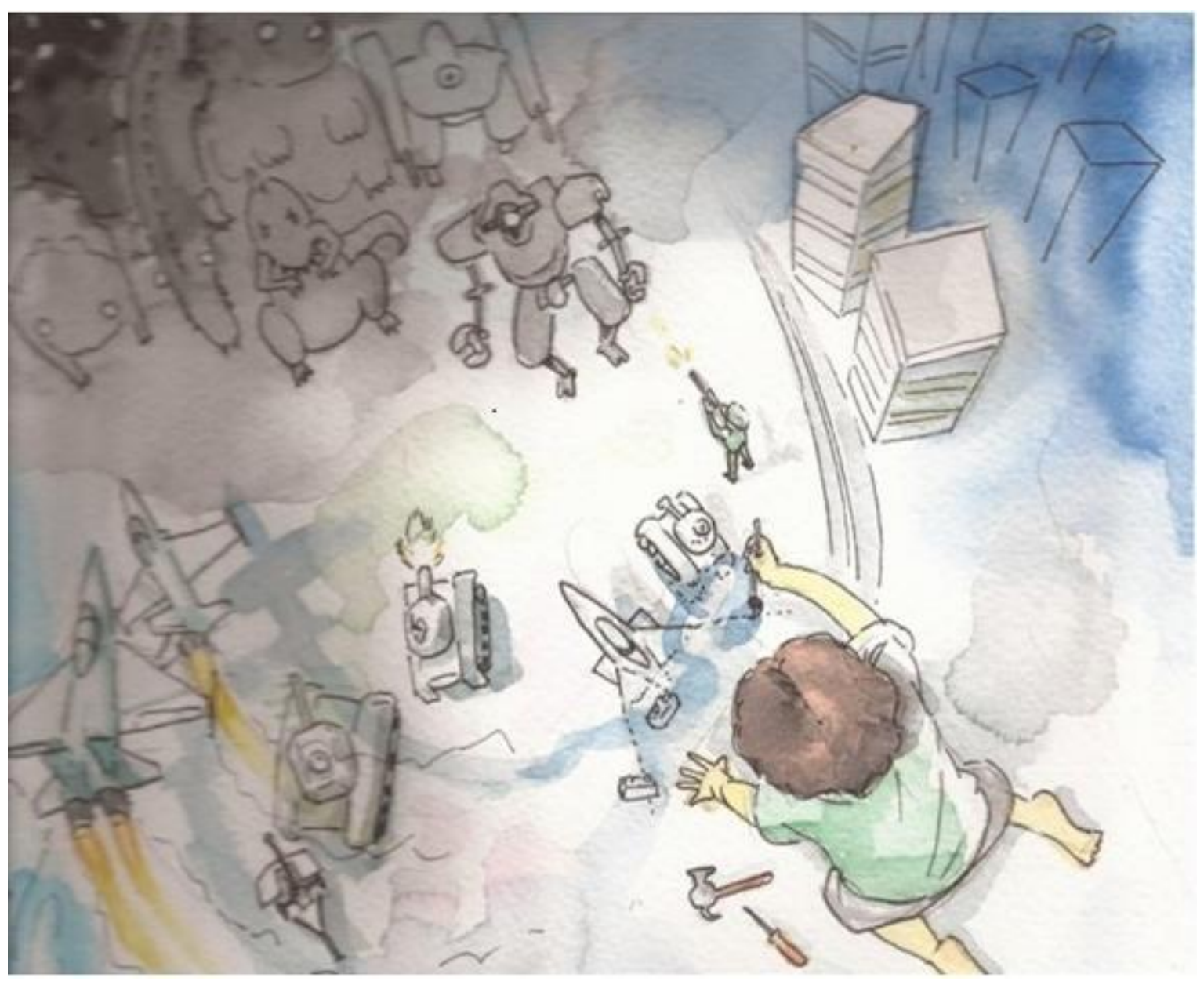

Figura 01: Aquarela - Ilustração Diário de campo de Elton Takumi Kawamorita.

Outras produções interessantes surgiram como o trabalho de Amália Barrio Rodrigues que apresenta a reprodução de imagens de sua infância (figs. 02, 03 e 04): 

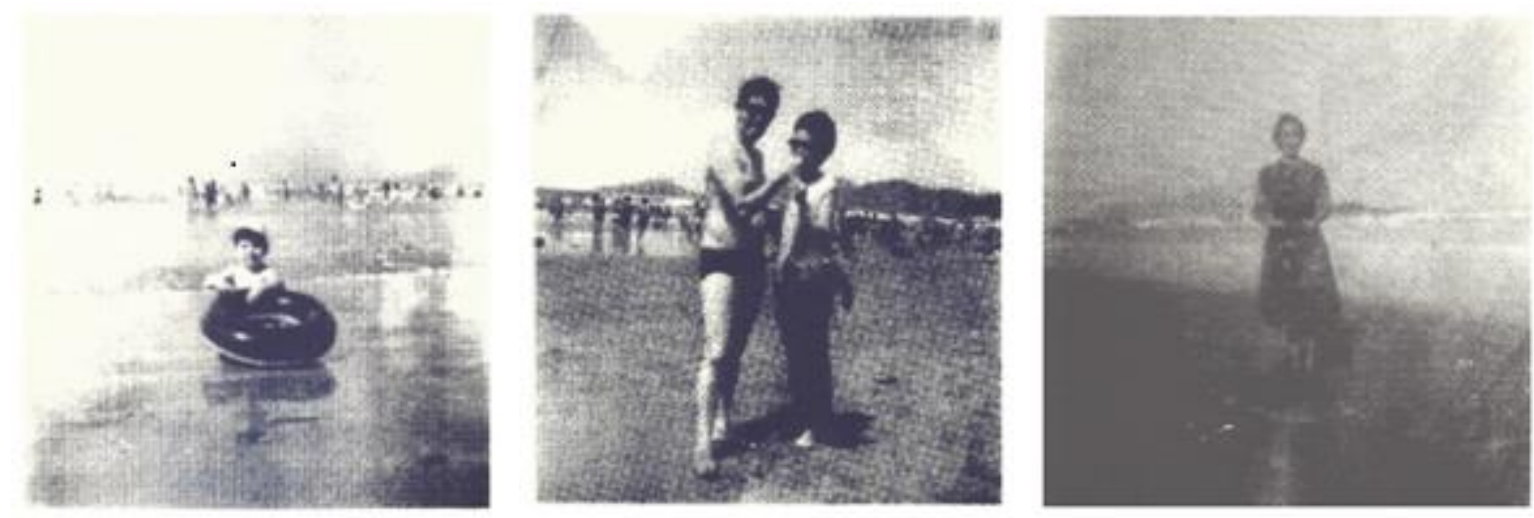

Figura 02: Reprodução de fotos extraídas do trabalho de Amália Barrio Rodrigues.

Figura 03: Reprodução de fotos extraídas do trabalho de Amália Barrio Rodrigues.

Figura 04: Reprodução de fotos extraídas do trabalho de Amália Barrio Rodrigues.

A liberdade de produzir escritos, desenhos, pinturas e fotografias foi amplamente privilegiada nos Diários de Campo, ou Diário de Insights. Registros nos quais os autores puderam divagar escrevendo observações espontâneas ou rascunhando desenhos, como neste exemplo da figura 05. Inscrevendo suas observações, ideias, valores, expressavam suas vozes substituindo a escrita essencialmente descritiva pela observação livre e criativa. Como afirma Loponte:

Contaminar nossos processos de formação inicial docente com uma atitude estética, que vai além de certa racionalidade e objetividade didáticas, pode nos ajudar a provocar nossos jovens alunos iniciantes no sentido de, quanto à docência, ousar mais em seus planejamentos, estratégias didáticas, modos de lidar com o conhecimento e com o cotidiano escolar, assim como com as novas gerações de alunos (LOPONTE, 2013, p. 15). 


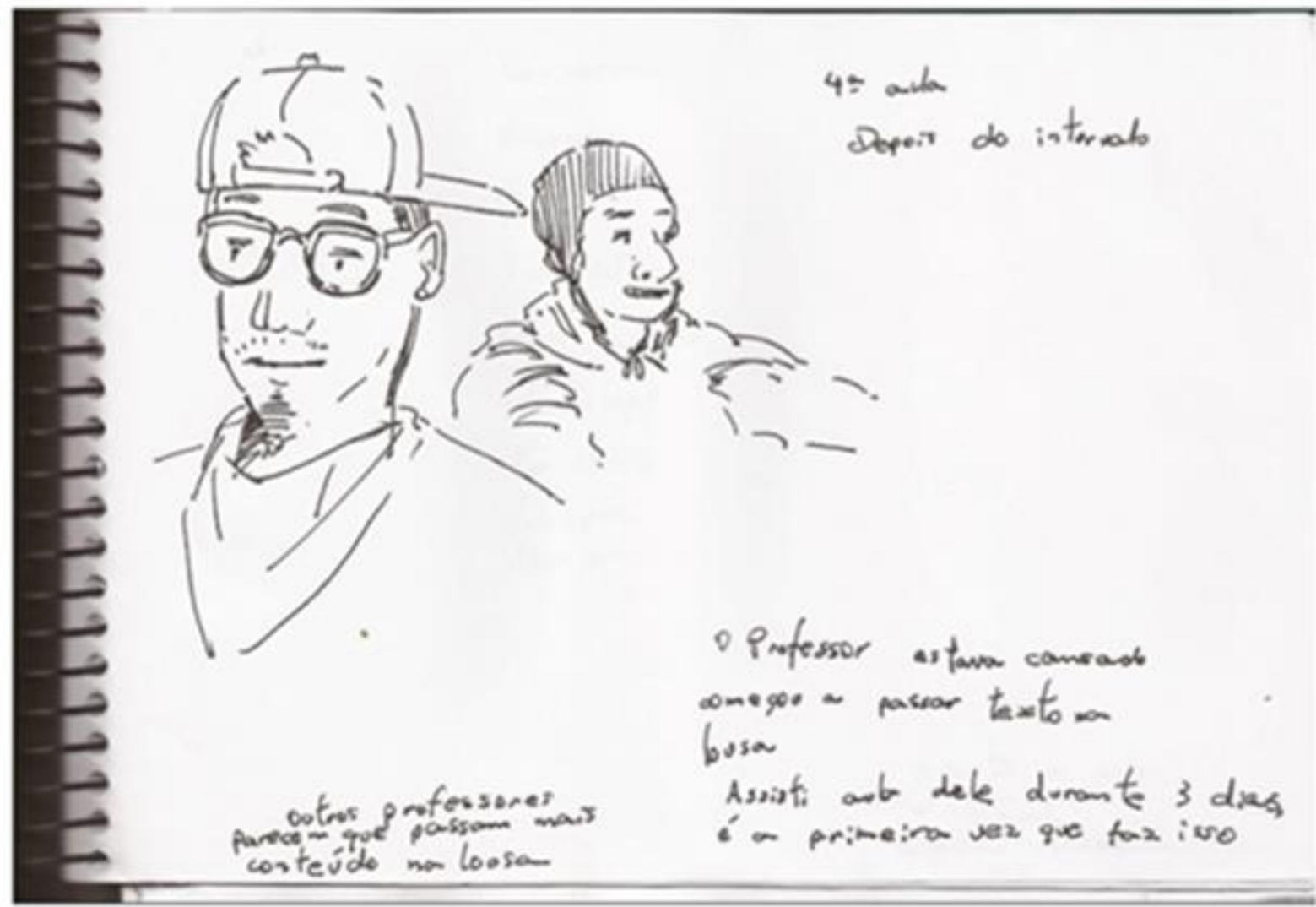

Figura 05: Desenho e escritos do Diário de Campo de Elton Takumi Kawamorita.

Então, escritos e imagens participavam das produções dos estudantes como preciosas informações inventariadas que viabilizavam a mensagem almejada pelo autor. Rita Irwin (2009, p. 93) explica que o caráter textual se integra com a visualidade, tanto ao se complementar como ao se refutar e se salientar: "Imagem e texto não duplicam um ao outro e, sim, ensinam algo de diferente e ainda, similar, permitindo que nos questionemos mais profundamente a respeito de nossas práticas." Pressuposto apresentado por Gustavo Lucatelli Castro neste trabalho de (fig. 06) que concatena palavras com imagens para expressar ideias a respeito das possibilidades que a arte é capaz de propiciar: 


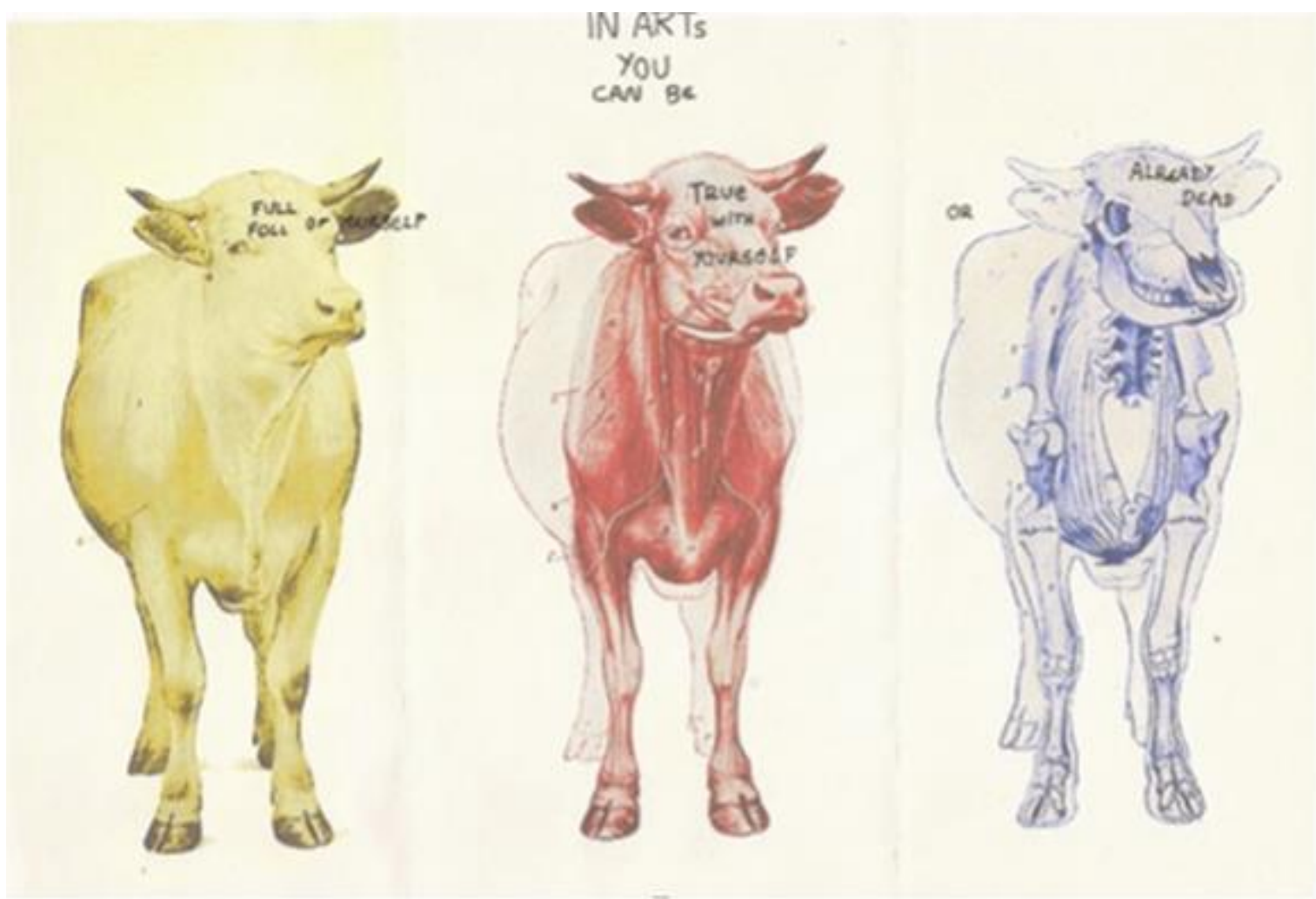

Figura 06: Imagens e escritos extraídas do trabalho de Gustavo Lucatelli Castro.

Durante nossas conversas, ressaltamos a importância da vivência do processo criativo pelo próprio arte-educador, tanto para beneficiar sua prática docente quanto para seu próprio proveito. Quando criamos algo que nos apraz, a energia liberada, a energia da criação nos dá a sensação de estarmos vivos e participantes do movimento do mundo. Hélio Oiticica dá o seguinte depoimento:

(...) sobrepujando todas as deficiências sociais, éticas, individuais, está uma necessidade superior, em cada um, de criar, fazer algo que preencha interiormente o vácuo que é a razão dessa mesma necessidade - é a necessidade de realização, completação (sic) e razão de ser da vida. (...) a arte é então uma etapa disso, passageira, sofrível d modificações com as que agora se operam. (OITICICA, 2006, s/p)

Assim, esses estudantes seguiam deixando através de suas produções artísticas e educativas: declarações, marcas, memórias, desejos, reflexões e imagens sobre os fenômenos experienciados.

Como nos fala Natalia Regina Gregorini sobre sua experiência com a gravura: 
No meu processo de aprendizagem notei que foi bastante importante o silêncio quase sempre presente nele, já que foi errando muitas vezes e tendo que refazer, que aprendi a maioria do que sei sobre gravura. A gravura é uma técnica de processo, de paciência, como já foi dito. Aprender seus segredos é se entregar a todos os acontecimentos dos processos, inclusive e quase que principalmente, aos erros (NATALIA REGINA GREGORINI, 2015).

A estesia da obra também reflete a representação da vida do artista, a qual vai incorporando e conectando a cada dia, novas ideias e associações urdindo uma tessitura da obra tramada com a vida. E é esse tecer que configura a autenticidade da obra - uma contribuição pessoal que mobiliza elementos capazes de desvelar os processos de produção do autor, suas experiências, valores, ideias e muitos outros aspectos. Não é somente o novo que deflagra sua autenticidade, mas a combinação da forma e conteúdo com os quais a obra vem, ou seja, a variação criativa em torno do tema é que faz com que o objeto seja renovado indefinidamente, perpetuando-se através de épocas. Dessa forma, a criação acontece por meio da trajetória das vivências pessoais objetivas e subjetivas do autor, sendo voltada ao seu desejo interior, descontaminada de interesses externos a ela, podendo exigir tempo e disciplina desse criador e até mesmo despertar nele sentimentos de frustração e desânimo.

A Crítica Genética consiste na pesquisa e análise dos documentos dos processos de criação em arte, como, "anotações, diários, esboços, maquetes, vídeos, contatos, projetos, roteiros, copiões" e é através dela que surge a crítica de processo desvelando as transformações progressivas da obra (SALLES, 2007). Esta abordagem reafirma a existência de percursos criativos em arte, quase sempre árduos e intensos que se valem de acertos, desacertos, pesquisas e construções de protótipos, que muitas vezes são desconhecidos - fator que acaba promovendo a ideia bastante recorrente do senso comum que julga que a obra nasce pronta.

Contudo exercitando a liberdade de criação na arte, tanto nossa quanto de nossos educandos poderemos estimular e ser estimulados a criar em outros campos.

Rita Irwin explica que o trabalho do artista-pesquisador-professor que tenta integrar teoria/pesquisa, ensino/aprendizado e arte/produção deve transcender a dialética e adentrar categorias mais complexas de intertextualidade e intratextualidade para que possa obter " ...uma visão multifacetada que encoraja a existência da 'terceiridade', um espaço 'no meio', entre e dentre as categorias" (2009, p. 88). A autora pontua que: 
Se concebermos pesquisa, ensino e produção de arte como atividades que se costuram e, através umas das outras, o intra e o entrelaçamento de conceitos, atividades e sentimentos, estaremos criando uma manta de similaridades e diferenças. (...) Onde duas estariam inclinadas em oposição dialógica, um terceiro espaço oferece um ponto de convergência, mesmo que ainda propicie divergência, no qual diferenças e similaridades estão costuradas juntas (IRWIN, 2009, p. 90).

Os trabalhos que os estudantes traziam refletiam momentos pontuais de seus processos vivenciais, porém é possível observar que as imagens representadas transcendiam estes objetivos primordiais. Neste trabalho (fig. 07) Guilherme Strafacci Orosco explora o imaginário, o movimento da figura e a transparência da aquarela:

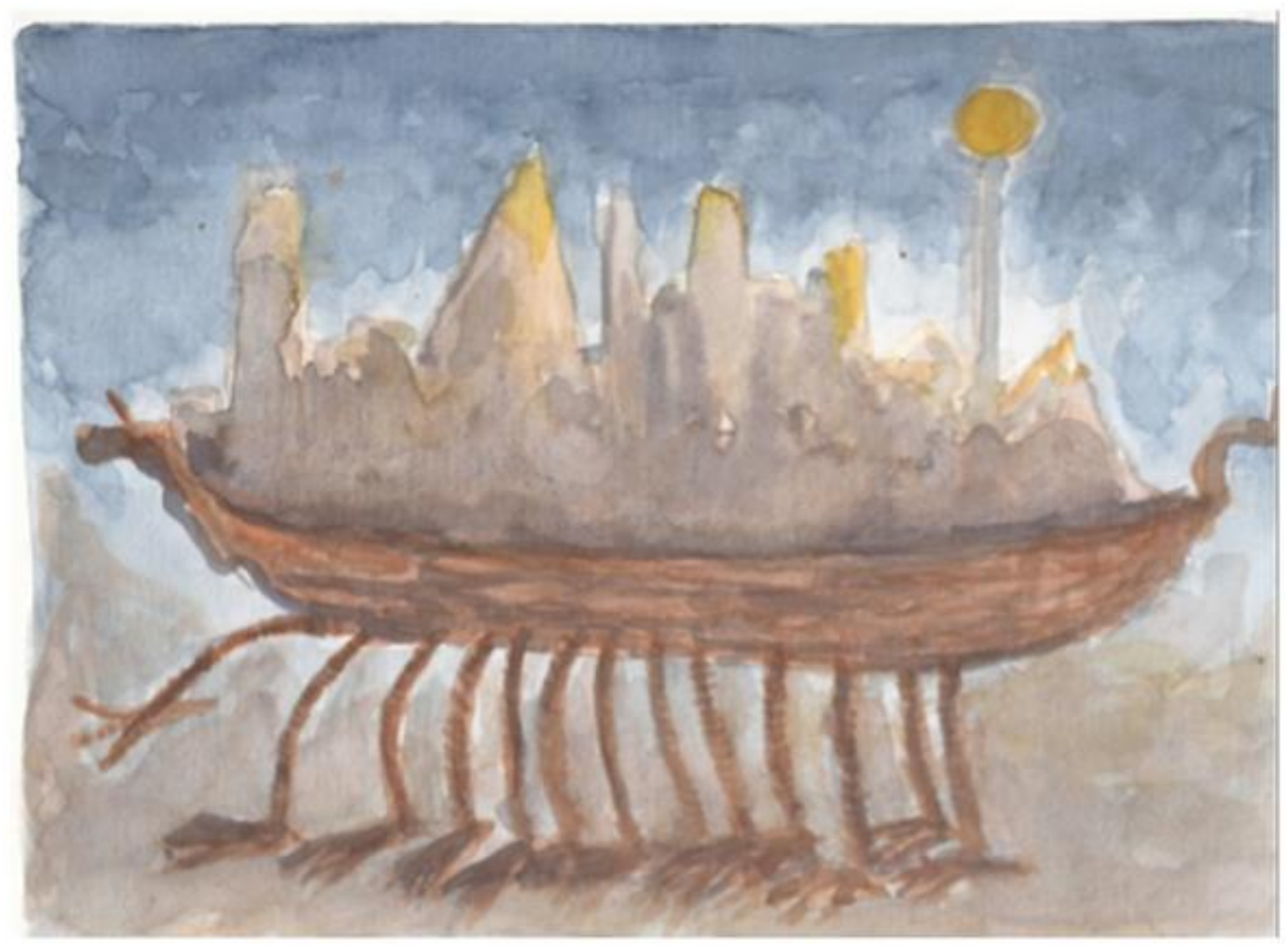

Figura 07: Aquarela de Guilherme Strafacci Orosco.

Os registros dos estudantes indicavam desejos na arte, na pesquisa e na vida, como neste depoimento de Caetano Capriolli Netto: 
Não há sentimento melhor do que sentir que fomos importantes para a vida de alguém. Acredito que meu objetivo como professor de artes é ensiná-los a se expressarem e entrarem em contato com seus sentimentos, emoções e experiências de vida. Com a arte somos capazes de dar um sentido a nossa existência e de nos tornamos mais críticos e capazes de questionarmos nossa realidade e as verdades existentes nela (CAETANO CAPRIOLLI NETTO, 2015).

Em sala discutíamos a importância do ensino de artes na educação diante daquela que efetivamente encontramos nas práticas cotidianas das instituições e espaços educacionais. Concordamos que muitas vezes os profissionais do ensino de artes se deparam com algumas confusões, tanto deles mesmos quanto de outros profissionais do ensino que estão diretamente relacionadas à compreensão com a qual concebem a área de conhecimento de artes e a área de conhecimento do ensino da arte. Confusões que dizem respeito a lacunas na formação, as quais muitas vezes, os envolvidos nem sabem que as têm.

Educa-se, ensina-se, nos parece, para que ninguém saia do próprio lugar, para que ninguém ouse ir além de si mesmo. Contraditoriamente, o ensino das artes, apesar de alimentar-se de uma forma ou outra da produção impensada e inusitada do campo artístico, domestica-se, apazigua-se, acomoda-se a estética fake escolar (LOPONTE, 2013, p. 179).

Esses estudantes buscavam respostas e caminhos para apaziguar insatisfações que emergiam do caos que muitas vezes se encontravam quando penetravam no campo de estágio. Muitas reflexões importantes sobre questionamentos internos foram feitas, como estas inscritas no relato da estudante Fernanda Costa Gaspar:

Acho que seria interessante notar, antes de tudo, que a compreensão do que eu produzo e assimilo sempre variou muito em relação ao que me ensinaram ser Arte; mesmo eu, que agora estou próxima de me formar como artista visual pela Unicamp, sempre achei que ou o termo era muito vago, ou então não me abraçava por completo. Talvez isso tenha menos a ver comigo, e mais a ver com a própria imprecisão que está sob o domínio da Arte, devido a fatores diversos culturais, acadêmicos, econômicos 
etc. de quem veicula e controla o termo, a ideia (FERNANDA COSTA GASPAR, 2015).

O trabalho intimista de Fernanda Costa Gaspar (fig. 08) expressa delicadamente a figura feminina ressaltando a textura do cabelo por meio do requinte linear:

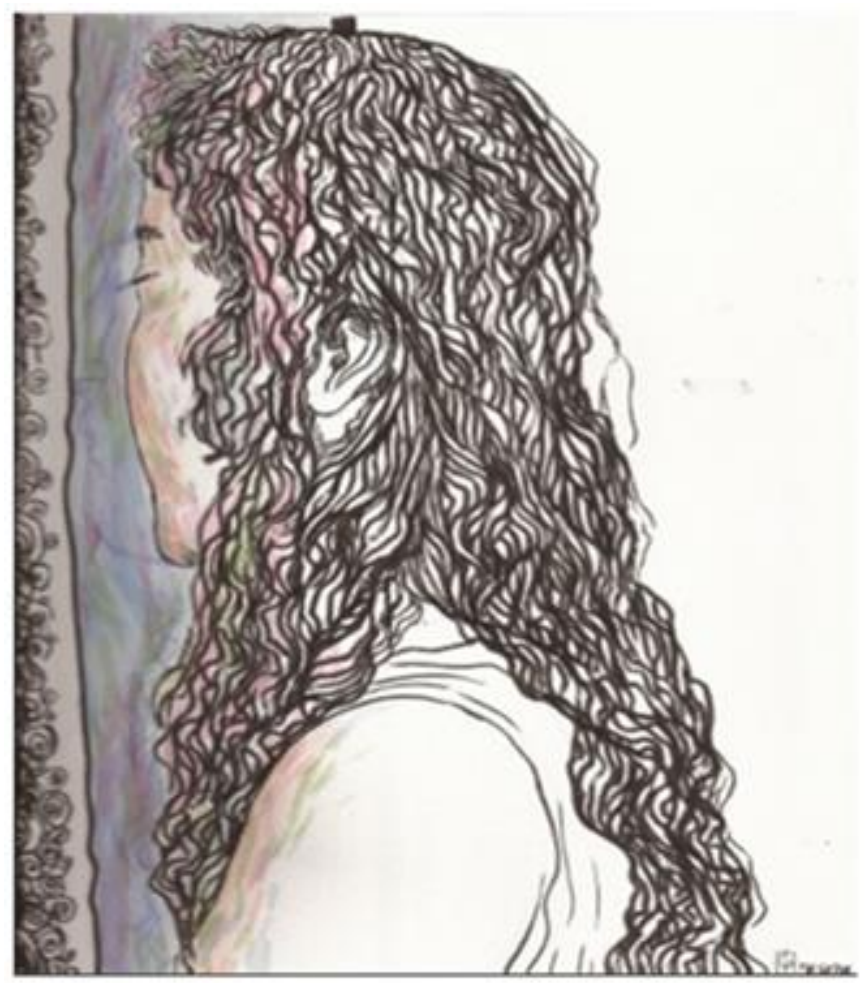

Figura 08: Desenho e pintura a nanquim de Fernanda Costa Gaspar.

Para alguns, a idealização do que seria a excelência no ensino de artes sofria uma derrocada vertiginosa originada pela distância que a realidade do estágio impunha contrapondo-se às muitas discussões teóricas desenvolvidas durante suas formações. Para outros, as instituições nas quais estagiavam supriam satisfatoriamente suas expectativas considerando-as difusoras de "um ensino de artes de qualidade". A turma continha não só estudantes prestes a assumir carreiras profissionais na área de artes, mas também um professor que já ministrava aulas em instituições de ensino público. Por isso nem todos vislumbravam o estágio como um ritual de passagem da vida estudantil para a vida profissional, circunstância que aliada à diversidade dos locais de estágio enriqueceu a série de discussões que iam sendo desenvolvidas. As reflexões desenvolvidas sobre as diferenças marcantes vindas de situações específicas e características de cada contexto de estágio formavam pontes que buscavam aprofundar a compreensão e a formulação de meios para superação dos problemas. 
Discutíamos sobre a constituição do ensino de artes como área de conhecimento que tem seu enfoque voltado não somente aos conteúdos das artes, mas às reflexões sobre a didática e os procedimentos metodológicos que envolvem a transmissão de seus conhecimentos e práticas de acordo com as múltiplas características, necessidades e diversidade dos contextos educacionais envolvidos. Além disso, defendíamos que é possível ensinar diversas disciplinas do currículo escolar através de um eixo metodológico enriquecido com práticas em artes sem que para isso seja estabelecida uma hierarquização da importância dos saberes difundidos nas áreas de conhecimento que serão exploradas. Mas para que todos possam adquirir ganhos nesse intercâmbio de conhecimentos é necessário que o profissional de ensino tenha clareza dos objetivos que pretende atingir e das estratégias que deverá desenvolver para atingi-los.

E tratando ainda da atuação profissional do docente em artes, tínhamos outro ponto importante a discutir que é a exigência vigente da polivalência como pressuposto obrigatório do desempenho do professor de artes. Imposição antiga que nós arteeducadores lutamos contra há muito tempo já que obriga a um único professor a incumbência de dar conta de todas as modalidades artísticas: Artes Visuais, Artes Cênicas, Dança e Música. Os estudantes já tinham consciência que essa atribuição extrapolante incide diretamente na desvalorização do ensino de artes, pois este último acaba configurando suas especificidades como meras atividades que ficam amalgamadas sem clareza de posição. Resoluções que levam ao retrocesso as diversas modalidades das artes já sedimentadas reconhecidas como áreas de conhecimento. Sobre isso Guilherme Strafacci Orosco relata:

(...) o pouco tempo disponível para as artes deve ser dividido entre todas as modalidades, e o professor deve ser multitarefas, fato que é comprovadamente impossível de ocorrer: cada professor de artes enfatiza mais sua especialidade, independente do que se pede no PCN, e com razão, uma vez que não receberam formação para tal (GUILHERME STRAFACCI OROSCO, 2015).

Outros reclames dos estudantes relacionados ao ensino público levantaram problemas que também já são bem conhecidos pelos arte-educadores: a carga horária insuficiente que causa a perda da unidade ou progressão didática; a falta de interação entre as disciplinas; a ausência de materiais e as salas de artes "adaptadas" precariamente. Guilherme Strafacci Orosco sugere: 
Se me fosse dada a oportunidade, eu alteraria as grades curriculares do ensino médio e proporcionaria aos alunos o direito de escolher que área das artes tem mais interesse em seguir para junto de um especialista desenvolver sua aptidão. Com isso, eu colocaria as aulas de artes em um contra turno, com um horário maior, sem a fragmentação em pequenas aulas de cinquenta minutos (GUILHERME STRAFACCI OROSCO, 2015).

Assim, nos debates defendemos que cada área de conhecimento é um componente curricular isolado dos demais, já que teatro, música, artes visuais e dança são disciplinas, especificidades autônomas que devem ser ministradas nas escolas por professores licenciados. Cada uma delas tem uma esfera de estudo e de práticas que correspondem a seus objetos e bibliografias especializadas.

Existe um paradoxo infrutífero que nós, arte-educadores (geralmente com formação modernista) acabamos conformando: Dialogamos muito pouco sobre as especificidades de outras áreas em artes, sendo que cada grupo acaba atuando, produzindo e difundindo conhecimentos na sua própria especificidade. Enquanto na lei prevalece a contestada polivalência, nas incursões teóricas de atividades de pesquisa no ensino de artes, os profissionais das artes plásticas, das artes cênicas, da música e da dança, conhecem pouco dos autores atuais das outras áreas que não são as suas. Compartilham também poucos conhecimentos relativos às particularidades de suas práticas.

Assim, em classe foi possível discutir essas questões fazendo uma autocrítica interessante, pois como refletimos, se pudéssemos diluir essas fronteiras, dialogando com outros profissionais de outras áreas de artes, teríamos grupos mais integrados e mais enriquecidos.

Também discutimos a importância da atividade de pesquisa, a qual Selma G. Pimenta propõe ser imprescindível no desenvolvimento do estágio: "... o estágio como pesquisa se coloca no momento atual como postura teórico-metodológica e desafio" (2006, p. 21). Porém é importante ressaltar que muitas vezes encontramos no ambiente educacional sujeitos que contradizem a referência teórica da pesquisa a qual estamos fundamentados. E assim, o que fatalmente ocorre é recair no erro de tentar mudar o sujeito e não o referencial teórico. Os conceitos não devem funcionar como moldes ou padrões, sendo que devemos estar atentos para nos deixar levar ou nos inspirar por nosso público e não tentando encaixá-lo em algum formato pré-establecido.

Em seu estágio, Gustavo Lucatelli Castro relata que foi bem recebido pelos professores, mas ressaltou uma série de problemas durante suas observações: 
Trabalhando as datas comemorativas e seguindo a apostila e cronograma do Estado, o conteúdo era dado às crianças de maneira um pouco engessada e antiquada, usando da fórmula de aula de cópia de longos textos biográficos sobre artistas famosos, dos quais as crianças em minhas conversas relatavam não conhecer, e que ao final das mesmas aulas permaneciam sem conhecer, pois muitas vezes os professores não chegavam a levar imagens das obras dos mesmos artistas ou quando sim forçavam atividades de desenho motivadas por "pinte igual", "siga os pontos" ou "copiem esse" que cansavam as crianças e que se mostravam inadequadas, numa olhada rápida nos cadernos de desenho livre nos quais as crianças se divertiam com o próprio estilo, para as idades e mesmo para o nível possível de compreensão. Acho importante sublinhar que muitas vezes a mesma aula era dada para a quinta e para a sexta série (GUSTAVO LUCATELLI CASTRO, 2015).

Para Gustavo Lucatelli Castro, um projeto educativo que pudesse trazer ganhos para essas crianças deveria abandonar a apostila para aproveitar melhor o tempo das aulas. Sugere que fossem feitos três encontros sobre um determinado artista, nos quais elementos da cultura do artista estudado seriam apresentados, assim como, imagens de suas obras dos. Os materiais relativos a esse artista também seriam explorados através da livre experimentação. Ele também propôs que conteúdos interdisciplinares fossem desenvolvidos nesse encontro. Tais encontros levariam em consideração a opinião e a conversa com as crianças, sempre trabalhando seja no desenho, na pintura ou em atividades corporais o desenvolvimento cognitivo e manual através da experimentação. Isso tudo se não em horário de aula, então durante as tardes em que escola fica aberta oferecendo oficinas e aulas de reforço. Mas o Gustavo não pode apresentar suas ideias porque em seu estágio somente Ihe foi dada a chance de observar. Sobre esse ponto, Selma Pimenta defende que no estágio, é imprescindível superar a dicotomia entre teoria e prática e além dos conhecimentos da disciplina que vai estagiar, o estudante deve desenvolver o envolvimento com a instituição, permitindo-lhe que conheça sua historicidade, identifique seus resultados, os impasses que apresenta e suas dificuldades: Esse conhecimento envolve o estudo, a análise, a problematização, a reflexão e a proposição de soluções às situações de ensinar e aprender. Envolve também experimentar situações de ensinar, aprender a elaborar, executar e avaliar projetos de 
ensino não apenas nas salas de aula, mas também nos diferentes espaços da escola (PIMENTA, 2006, p. 20).

Propus aos estudantes que pesquisassem uma atividade que pudesse conjugar algum interesse expresso por seu público em especial e a arte contemporânea. Nesta oportunidade, poderiam trazer imagens de artistas que tivessem conexão com a proposta. Guilherme Galindo propôs o seguinte trabalho: O exercício de uma reestruturação da identidade visual da marca da Coca-cola. Imagens dos trabalhos de Cildo Meireles e Tunga foram propostos para ilustrar essa atividade. Fernanda Costa Gaspar utilizou seu Diário de Campo para esboçar as ideias que pretendia desenvolver (fig. 09):

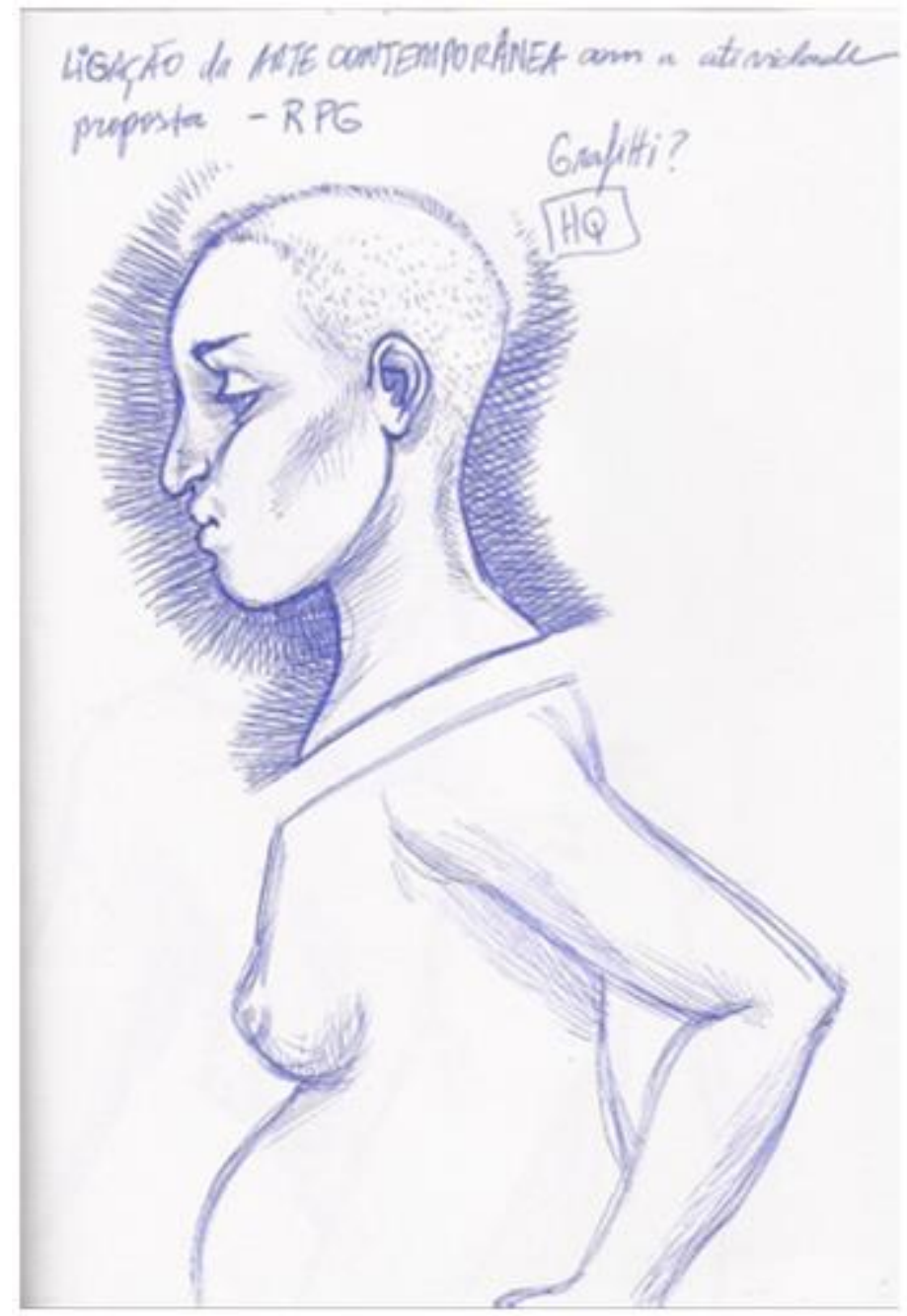

Figura 09: Desenhos e escritos do diário de campo de Fernanda Costa Gaspar.

Algumas questões levantadas abordaram as relações de poder que existem nos ambientes de ensino público, assim como a ausência de autonomia relacionada às 
decisões tomadas. Para Caetano Capriolli Netto é necessário que na escola haja um espaço democrático, e em suas análises, comenta:

Minha impressão do problema é que, para os professores e até mesmo para a escola, exigem que o aluno já tenha essas habilidades pré-dispostas ou aprendidas em casa. Em outras palavras, na escola se ensina conteúdos e não convivência (CAETANO CAPRIOLLI NETTO, 2015).

Por meio de seus trabalhos, a turma podia manifestar suas contestações expressando dúvidas e anseios que fatores imprevisíveis e contradições decorrentes da prática em sala de aula causavam no seu estado de ânimo. Elton Takumi Kawamorita expressou algumas dúvidas e sentimentos que poderiam estar relacionados a instâncias mais amplas relacionadas a sua vida (fig. 10):
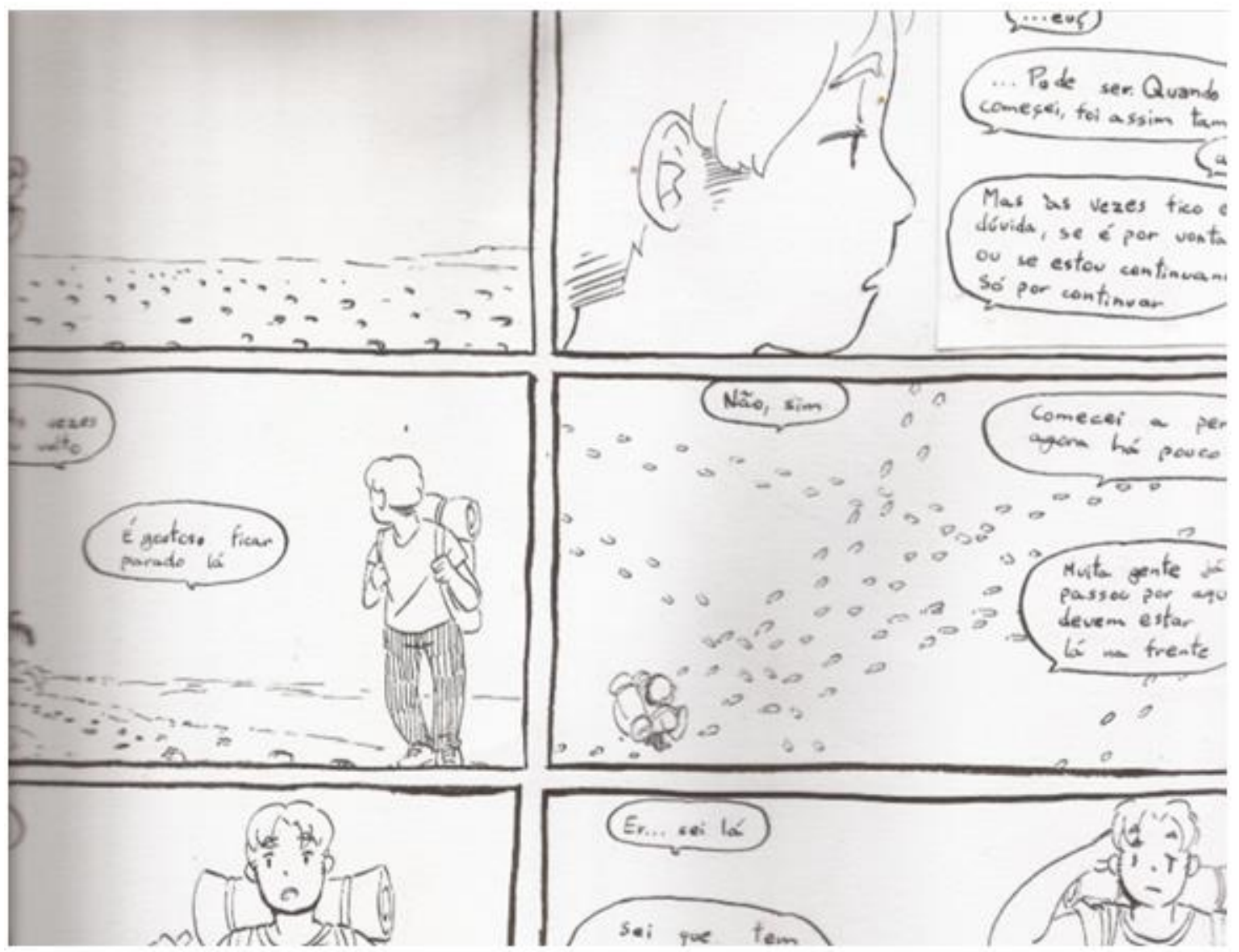

Figura 10: História em quadrinho de Elton Takumi Kawamorita.

Revista Digital do LAV - Santa Maria - vol. 10, n. 2, p. 140 - 161 - mai./ago. 2017 ISSN 1983 - 7348 http://dx.doi.org/10.5902/1983734827402 
Os estudantes que estagiavam nas instituições particulares especializadas em ilustração e desenho, trouxeram algumas informações diferentes, como por exemplo: somente 5 a 10 alunos por sala; espaços similares ao de uma casa com estruturas variadas; desenvolvimento de ambientes descontraídos com paredes decoradas com trabalhos de professores e ilustradores famosos convidados a visitar a escolar e interagir com os alunos; autonomia do professor; propostas interdisciplinares e realização de exposições. Já para Marion Franzini Chatton que estagiou com crianças e adolescentes de 6 a 16 anos foi possível desenvolver atividades de pintura em tela. Junto com a equipe que atende esses portadores de necessidades especiais, Marion optou pelo "sonho" como tema para desenvolver as pinturas, pois acredita que este é um objeto pelo qual a imaginação não tem limites, passível de estimular a criatividade das crianças. Conta que juntamente com a equipe, buscou:

(...) mostrar que existem diversas maneiras de pintar e que cada um pode escolher a que preferir de acordo com o efeito que quer atingir. Deixar que cada um represente seu sonho da maneira que achar mais adequado é essencial para o aluno criar autonomia e, em alguns casos, descobrir um estilo próprio de pintura. (...) por se tratarem de crianças surdas, é de suma importância que elas tenham liberdade de se expressar de outra maneira que não a fala. A questão da visualidade com os surdos é essencial para o aprendizado e desenvolvimento da autonomia deles, assim, com esse projeto que propusemos esse semestre, essas crianças puderam desenvolver suas habilidades manuais e criativas, aprendendo uma nova possibilidade de se expressa (MARION FRANZINI CHATTON, 2015).

Para Rita Irwin, o acrônimo A/r/t (artist-researcher-teacher) é apreciado porque...

... não apenas reconhece o papel de cada indivíduo, mas também possibilita que todos nós tenhamos um momento de imaginação ao apreciarmos e entendermos que os processos e produtos envolvidos na criação da obra de arte, não importando se são objetos ou tarefas profissionais, são formas exemplares de integração entre saber, prática e criação. (2009, p. 92) 
Nesta proposição, Marion elaborou estes trabalhos (figs. 11, 12 e 13) utilizando materiais próprios dos ambientes escolares: giz de cera e papel sulfite.
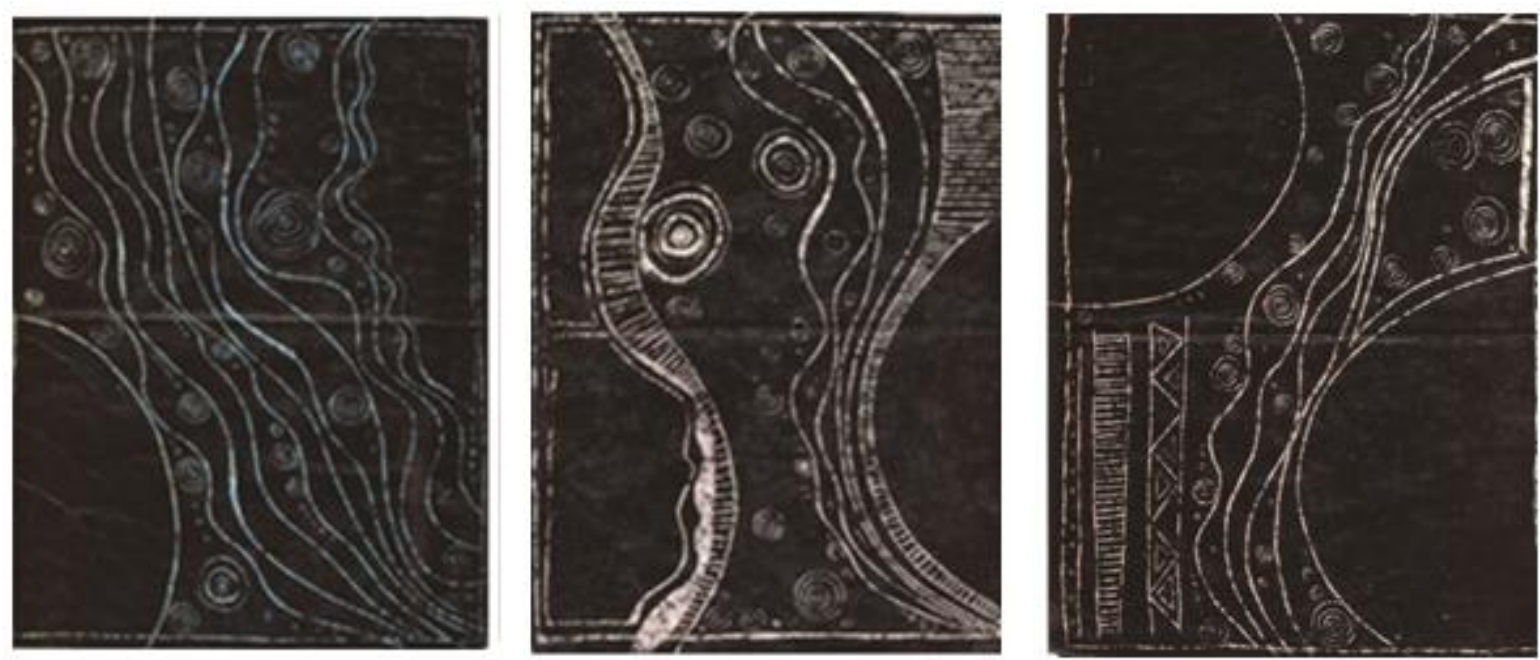

Figura 11: Trabalho de pintura em giz de cera com raspagem de Marion Franzini Chatton.

Figura 12: Trabalho de pintura em giz de cera com raspagem de Marion Franzini Chatton.

Figura 13: Trabalho de pintura em giz de cera com raspagem de Marion Franzini Chatton.

O relato de Natalia Regina Gregorini tratou de uma prática educacional enriquecida pela vivência intergeracional:

É interessante notar como essas diferenças de idades colaboram para uma riqueza maior ainda de aprendizagem. Os mais velhos relatam suas experiências e enriquecem maravilhosamente $o$ convívio. É interessante também que, em alguns alunos, os de idade mais avançada, nota-se que frequentam o curso não mais para aprender ou desenvolver seus trabalhos artísticos, mas para estar ali e fazer parte dessa comunidade. Eles produzem seus trabalhos, é claro, mas de uma forma muito descompromissada e livre. (...) O que mais me encanta em estar neste curso é a leveza. É o estar ali com calma e leveza desses alunos (NATALIA REGINA GREGORINI, 2015).

Se o que encanta Natalia é leveza é possível perceber que também o aspecto lúdico é uma particularidade imanente em seu trabalho (fig. 14):

Revista Digital do LAV - Santa Maria - vol. 10, n. 2, p. 140 - 161 - mai./ago. 2017 ISSN 1983 - 7348 http://dx.doi.org/10.5902/1983734827402 
Figura 14: Desenho em lápis pastel de Natalia Regina Gregorini.

A produção realizada durante a disciplina possibilitou a concretização de uma exposição de artes que foi intitulada Arte \& Estágio: Vivências e Percursos Poéticos (fig. 15). Realizada no $1^{\circ}$ piso da Biblioteca Central Cesar Lattes - BCCL da Unicamp de 16 a 30/11/2015 contou com o apoio da Biblioteca e da Galeria do Instituto de Artes da Unicamp - GAIA. Como a Biblioteca Central Cesar Lattes é um dos espaços culturais mais importantes da Universidade, a apropriação e instalação da exposição nesse espaço ampliou o reconhecimento e a valorização dos objetos artísticos desses jovens no ambiente acadêmico. Além disso, através de sua concretização, essa exposição permitiu que as trajetórias pessoais e coletivas fossem revisitadas esteticamente por seus autores rememorando a experiência de estágio e compartilhando essa vivência com outros públicos. 


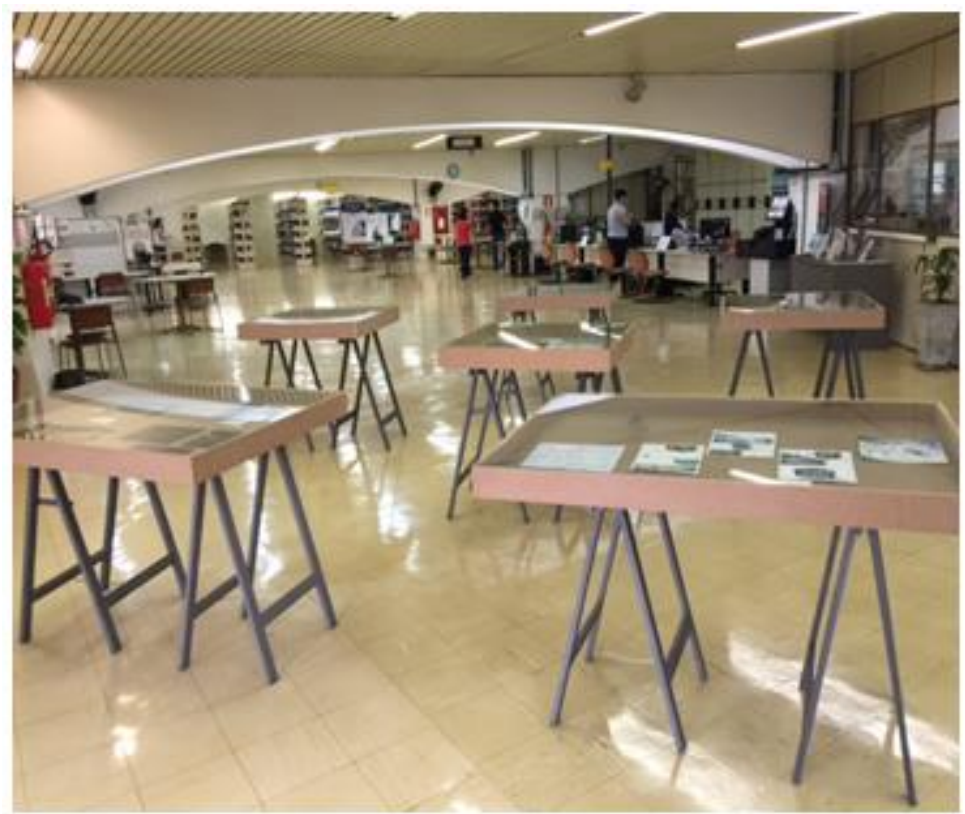

Figura 15: Foto da Exposição Arte \& Estágio: Vivências e Percursos Poéticos.

\section{Considerações Finais}

Sendo o estágio uma etapa marcante da vida profissional deve estimular o debate aberto e criador que viabilize meios potenciais de ação, tanto a nível pessoal quanto a nível coletivo, capazes de contribuir com a educação que prima pelo caráter humanizador da criação. Os diversos escritos e as produções em artes dos estudantes geraram olhares e reflexões significativas para o a área do ensino de artes, além da ampliação de pressupostos teóricos, metodológicos, psicológicos e filosóficos da área do estágio e da docência. Dessa forma, esses trabalhos falaram por si, pois através de suas expressões foram capazes de facilitar os caminhos trilhados pelos estudantes, assim como seus anseios. Ao se corporificarem em trabalhos de artes, os desafios que foram sendo delineados no campo empírico foram enfrentados não só por aspectos intelectivos, mas também pela potencialidade catártica da experiência estética. Através das atividades desenvolvidas, este grupo concretizou um conjunto de fazeres ligado a uma proposta cognitiva e sensível que remete à noção de formação. Uma realização conquistada diante da complexidade do entrelaçamento de identidades que envolve o estágio em artes, ou seja, os diversos papéis que os estudantes estagiários assumem, como: futuros professores, pesquisadores e produtores de artes.

Como propõe a metodologia da $\mathrm{A} / \mathrm{r} /$ tografia, além das experiências de pesquisa fomentadas nas leituras e discussões e atividades pedagógicas vividas diretamente com seus públicos no campo de estágio, os estudantes usufruíram de muitas vivências 
criativas que incluíram produções gráficas, pictóricas e textuais, representando suas vivências e compreensões e questionando suas posições como estudantes estagiários. Dessa forma, a proposta não se voltou a motivar os estudantes a assumirem-se como artistas ou professores a partir das experiências vivenciadas, mas, sobretudo a compreenderem que além de suas práticas de pesquisa e ensino, também seus processos e produtos foram capazes de complementar suas reflexões, interpretações e atuações. E ainda, propiciar a noção de que este processo nunca termina, pois mesmo quando se tornarem profissionais, deverão seguir se reatualizando em todas as instâncias, sejam elas de cunho investigativo, criativo, cognitivo e/ou prático. Ou seja, projetar uma aspiração que reflete a vontade de todos $a / r /$ tegrafistas que buscam aprofundar e refinar suas atuações intelectuais, emocionais e empíricas de modo contínuo.

Acrescente-se a essa proposta o trabalho no ensino de artes relacionado à nossa tomada de consciência sobre aspectos pertinentes à influência de poderes hegemônicos e supostas formas de colonialismo cultural que minimizam a importância da arte contemporânea e da arte popular na arte-educação.

O comprometimento desses estudantes fomentou a partilha de seus anseios, convicções e a compreensão profunda da necessidade da entrega à totalidade da experiência, das imersões teóricas e do reconhecimento de aportes que apoiaram as muitas vivências experienciadas na prática docente.

\section{Referências Bibliográficas}

ALBANO, Ana A. Histórias de Iniciação na Arte. Disponível em: <http://www.arquetipica.com.br. > Acesso em: 20 abr. 2005.

SALLES, Cecilia A.; CARDOSO, Daniel R. Crítica Genética em Expansão. In Cienc. Cult. vol.59 no.1 São Paulo Jan./Mar. 2007

CAETANO CAPRIOLLI NETTO. Relato. Campinas. São Paulo, 21, outubro, 2015.

CERTEAU, M. L'invention du quotidien. L'arts de faire. Paris: Gallimard, 1990. A invenção do cotidiano. Artes de fazer. Tradução Ephaim F. Alves. Petrópolis: Vozes,1996.

CHARTIER, R. A história cultural. Entre práticas e representações. Lisboa: Difel, 1990.

FERNANDA COSTA GASPAR. Relato. Campinas. São Paulo, 21, outubro, 2015.

FREIRE, Paulo. Pedagogia da autonomia: saberes necessários à prática educativa. 21 ed. São Paulo: Editora Paz e Terra, 2002. 
GUILHERME OROSCO. Relato. Campinas. São Paulo, 21, outubro, 2015.

GUSTAVO LUCATELLI CASTRO. Relato. Campinas. São Paulo, 21, outubro, 2015.

IRWIN, Rita L. A/r/tografia: uma mestiçagem metonímica. In Interterritorialidade mídias, contextos e educação. BARBOSA, Ana Mae; AMARAL Lilian (org.) São Paulo: Editora Senac São Paulo e Edições SESC, 2009. p 87-104.

LOPONTE, Luciana G. Arte para a Docência: estética e criação na formação docente.

Revista Arquivos Analíticos de Políticas Educativas, Estados Unidos, v. 21, p. 1-18, jan. 2013.

MARION FRANZINI CHATTON. Relato. Campinas. São Paulo, 21, outubro, 2015.

NATALIA REGiNA GREGORINI. Relato. Campinas. São Paulo, 21, outubro, 2015.

OITICICA, Hélio. Programa Ambiental. In 27a Bienal de São Paulo. Como Viver Junto.

São Paulo: Fundação Bienal, 2006.

PIMENTA, Selma G.; LIMA, Maria S. L. Estágio e docência: diferentes concepções. In Revista Poíesis -Volume 3, Números 3 e 4, pp.5-24, 2005/2006

RANCIÉRE, Jacques. The politics of aesthetics. The distribution of the sensible. New York: Continuum, 2004.

'Graduação em Lic. Educação Artística com Hab. Artes Plásticas pela Faculdade de Belas Artes de São Paulo (1980), Especialização em Arte e Tecnologia pela Faculdade de Belas Artes de São Paulo (2002), Especialização em Expressões Criativas pela Faculdade de Ciências da Saúde (2013), Mestrado em Artes Visuais pelo Instituto de Artes da Unesp (2005), Doutorado em Educação pela Universidade Estadual de Campinas - FE Unicamp (2012), Pós-doutorado em Educação pela Unesp de Rio Claro (2016). É professora universitária e artista plástica, tendo experiência profissional na área do Ensino Superior, Médio e Fundamental. Atualmente é coordenadora pedagógica do Curso de Psicopedagogia da Faculdade Iescamp em Campinas. Leciona no Ensino Superior, nos cursos de Pós-graduação e Graduação nas áreas de Pedagogia e Artes Visuais, nas seguintes disciplinas: Metodologia da Pesquisa, Percepção e Expressão Plástica, Expressões Criativas, Metodologia do Ensino de Artes, Estágio Supervisionado em Artes. Filiação Grupo de Pesquisa - Grupo de Estudos e Pesquisas Linguagens Experiência e Formação - Universidade Estadual Paulista - UNESP - Campus Rio Claro/SP - Instituto de Biologia - Departamento de Educação

Enviado em: 29 de maio de 2017.

Aprovado em: 16 de agosto de 2017.

Revista Digital do LAV - Santa Maria - vol. 10, n. 2, p. 140 - 161 - mai./ago. 2017 ISSN 1983 - 7348 http://dx.doi.org/10.5902/1983734827402 